\title{
GESTÃO DEMOCRÁTICA COMO CONDIÇÃO DE QUALIDADE: A FORMA DE PROVIMENTO DO DIRETOR ESCOLAR NAS REDES MUNICIPAIS BRASILEIRAS E A RELAÇÃO COM INDICADORES E RESULTADOS EDUCACIONAIS DE 2015 \\ DOI: $10.5902 / 2318133831894$
}

\author{
Marcus Quintanilha da Silva \\ Universidade Federal do Paraná, Brasil.
}

\begin{abstract}
Resumo
O presente trabalho tem dois objetivos: atualizar o panorama das formas de provimento do diretor escolar e analisar comparativamente indicadores educacionais e de contexto em grupos categorizados pelo provimento do diretor, só por eleição, indicação ou formas mistas, com delimitação a escolas que só ofertam os anos iniciais do ensino fundamental em 2015. Pela abordagem quantitativa, utilizou-se uma análise exploratória comparativa e o diálogo com a literatura. Os resultados evidenciaram maior homogeneidade e uma diferença de $5 \%$ a $20 \%$ nas médias dos indicadores utilizados na análise - Ideb, IDHM, ICQ - e proficiências em Língua Portuguesa e Matemática dos anos de 2015, exceção ao IDHM, de 2010, em favor do grupo de redes municipais dos diretores eleitos.

Palavras-chave: forma de provimento; indicadores educacionais; gestão democrática.
\end{abstract}

\section{DEMOCRATIC MANAGEMENT AS A QUALITY CONDITION: THE FORM OF THE SCHOOL DIRECTOR'S PROVISION IN THE BRAZILIAN MUNICIPAL NETWORKS AND THE RELATIONSHIP WITH INDICATORS AND EDUCATIONAL RESULTS OF 2015}

\begin{abstract}
The present work has two objectives: to update the panorama of the forms of provision of the school director and comparative analysis of educational and context indicators in groups categorized by the director's appointment, only by election, indication or mixed forms, with delimitation to schools that only offer the initial years of elementary education in 2015. Through a quantitative approach, a comparative exploratory analysis and the dialogue with the literature. The results showed greater homogeneity and a difference of $5 \%$ to $20 \%$ in the means of the indicators used in the analysis - Ideb, IDHM, ICQ - and proficiencies in Portuguese and Mathematics of the years 2015, exception to the HDI, of 2010, in favor of the group of elected directors' municipal networks.

Key-words: form of provision; educational indicators; democratic management.
\end{abstract}




\section{Introdução}

á uma lacuna na literatura brasileira que trabalha a gestão democrática como um princípio de ensino e, concomitantemente, uma dimensão da qualidade educacional. Este myssing é delimitado pela ausência de empiria, em que alia a qualidade educacional à democratização das ações e os instrumentos de gestão democrática. Por isso, o sentido desse trabalho caminha na direção dessa problemática.

Todavia, há obstáculos no que se refere a um ponto de partida para um estudo empírico da efetividade da gestão democrática em termos de qualidade educacional. Para tal, este trabalho optou por escolher como ponto inicial a forma de provimento do diretor escolar, entendendo que são respostas diretas e mais confiáveis nos questionários de contexto da Prova Brasil e que não exigem um survey, observações ou entrevistas para coletar essas informações.

Portanto, o presente trabalho tem dois objetivos: atualizar o panorama das formas de provimento nas escolas municipais brasileiras e analisar comparativamente indicadores educacionais e de contexto em grupos de redes municipais com base em suas formas de provimento, delimitando os casos somente para as escolas que ofertam os anos iniciais do ensino fundamental. A justificativa para a delimitação é decorrente de dois motivos: a diferença entre o perfil de uma escola com essa referida sub-etapa no comparativo a uma escola que só oferte os anos finais do ensino fundamental ou outras etapas da educação básica e o fato de os indicadores educacionais utilizados - Índice de Desenvolvimento da Educação Básica e Índice de Condições de Qualidade -, terem como base a sub-etapa delimitada.

Para tais objetivos utilizou-se como fonte de informações os questionários de contexto do diretor e os resultados das proficiências em Língua Portuguesa e Matemática da Prova Brasil de 2015, assim como o Índice de Desenvolvimento da Educação Básica Ideb -, o Índice de Condições de Qualidade - ICQ - e o Índice de Desenvolvimento Humano Municipal - IDHM -, disponíveis no site do Inep ou no IBGE. A opção por desses indicadores e resultados se justifica pois, no caso das proficiências e o ldeb, são índices que avaliam a educação nos resultados dos alunos, em um caráter avaliativo da escola e do sistema, enquanto o ICQ avalia uma parte do processo educacional, com indicadores parciais que dependem, sobretudo, da ação da política educacional para sua maior mensuração, portanto, uma avaliação de sistema/rede. O IDHM entra como um indicador de contexto social e econômico, entendendo que este pode acompanhar os resultados acima propostos.

Inicialmente explora-se o panorama por escolas e redes de ensino das formas de provimento do diretor escolar do Brasil, utilizando os questionários de contexto do diretor da Prova Brasil de 2015. O cenário é de distância da efetividade da gestão democrática em termos de eleições como provimento ao cargo. Posteriormente, utilizando o Indicador de Forma de Provimento, categorizou-se grupos de redes municipais de diretores $100 \%$ eleitos, indicados e de outras formas de provimento ou mistas. A partir destes foram explorados comparativamente resultados de proficiências, Ideb, ICQ e IDHM. Os resultados convergiram para o primeiro grupo - redes municipais com diretores eleitos mais homogêneo e, em consequência, com médias maiores de resultados que os demais. 


\section{Metodologia}

Trata-se de uma análise exploratória que reunirá alguns indicadores e resultados educacionais do ano de 2015 - exceção ao IDHM, de 2010 -, em torno da categorização das redes municipais pela forma de provimento. Utilizou-se para este trabalho o Índice de Condições de Qualidade - ICQ -, o Índice de Desenvolvimento da Educação Básica - Ideb -, os resultados de proficiência da Prova Brasil em Língua Portuguesa e Matemática e o Índice de Desenvolvimento Humano Municipal - IDHM.

O Ideb é um indicador consolidado na educação brasileira. Ele lida com proficiências de língua Portuguesa e Matemática, além das taxas de rendimento, calculando um indicador de 0 a 10 que venha a aferir a qualidade educacional da escola, rede e sistema. Há uma ampla literatura que critica esse aspecto atribuído ao referido indicador (Silva 2017a; Silva, 2017b), todavia, trata-se de um número bastante utilizado no monitoramento das políticas educacionais e amplamente reconhecido pela comunidade escolar.

O IDHM é calculado decenalmente e considera três dimensões: educação, longevidade e renda. Para tal, utilizou-se os dados do Censo de 2010, sendo calculado pelo IBGE. Compreende-se um IDHM baixo o intervalo menor que 0,499 , considerando a escala do indicador de 0 a 1 , de 0,500 a 0,799 um índice médio e acima desse quantitativo um desenvolvimento humano alto.

O ICQ é um indicador desenvolvido pelo Núcleo de Políticas Educacionais da Universidade Federal do Paraná, trabalhado em um programa de pesquisa financiado pelo Observatório de Educação do Inep e descrito metodologicamente em Gouveia, Souza e Schneider (2011). Ele consiste em olhar para a qualidade educacional em termos de condições de oferta, utilizando como fonte de informação os questionários de contexto da Prova Brasil. Como o indicador é formado por três indicadores parciais - Índice de Condições do Professor, Índice de Condições Materiais da Escola e Índice de Condições de Gestão - três dos quatro questionários envolvidos no certame são utilizados para cada um dos indicadores. A figura abaixo resume a dinâmica do mesmo.

Figura 1 -

Dinâmica do índice de condições de qualidade.

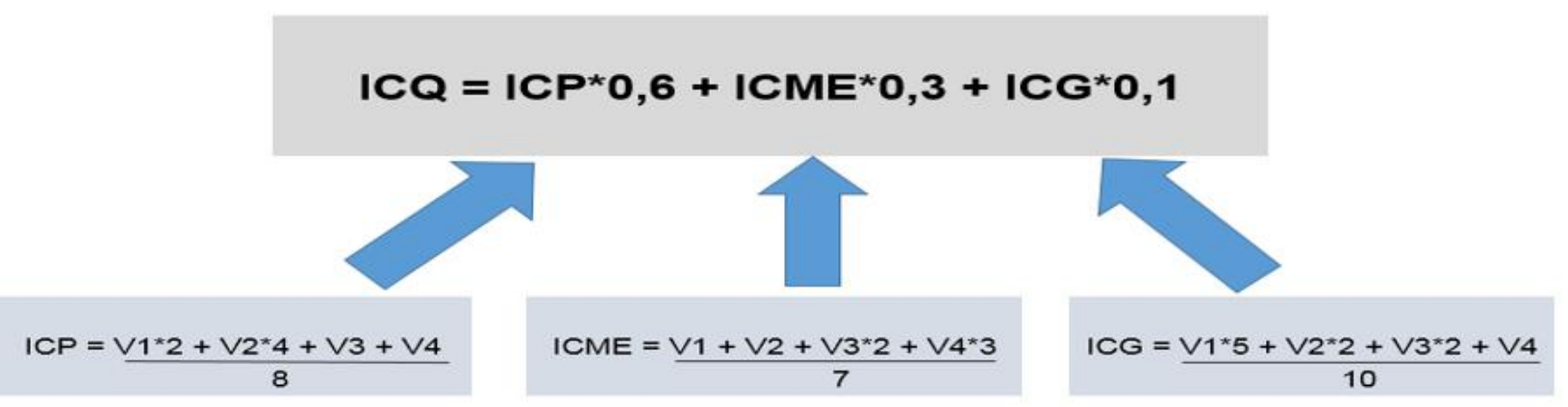

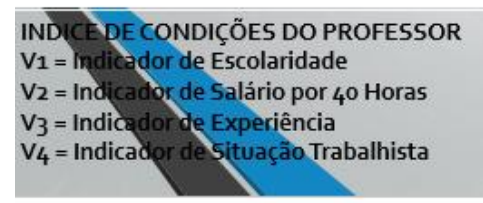

Fonte: Silva (2017).
INDICE DE CONDIÇÕES MATERIAIS DA ESCOLA V1 = Indicador de Conservação das Condições Fisicas $V_{2}=$ Indicador de lluminação e Ventilação $V_{3}=$ Indicador para Computadores e Internet

$V_{4}=$ Indicador para Equipamentos Eletrônicos
INDICE DE CONDIÇÕES DE GESTÃO V1 $=$ Indicador de Salário

$V_{2}=$ Indicador de Forma de Provimento $\mathrm{V}_{3}=$ Indicador de Conselho de Escola $\mathrm{V}_{4}=$ Indicador de Projeto Político Pedagógico 
A mensuração do indicador varia de 0 a 1 , assim como todos seus indicadores parciais e suas variáveis. Interessa, para esse momento, o Índice de Condições de Gestão, pois uma de suas variáveis, a forma de provimento, foi utilizada nesse texto como parâmetro de análise e categorização das redes municipais em termos de condições de oferta. Portanto, é necessário conhecer a pergunta da Prova Brasil e como a variável se quantifica.

Quadro 1 -

Perguntas que compõem a variável Indicador de Forma de Provimento (V2) com base nos questionários de contexto do diretor da Prova Brasil de 2015.

\begin{tabular}{|c|c|c|}
\hline Variável & Identificação da Questão & Pergunta \\
\hline V2 & Q14 & Você assumiu a direção desta escola por meio de: \\
\hline
\end{tabular}

Fonte: Questionários de contexto da Prova Brasil (2015).

A referida questão foi trabalhada nos estudos supracitados, considerando que a maior mensuração seria a que mais se aproxima em um contexto de efetividade da democracia nas escolas, ou seja, quanto maior o valor, o provimento do diretor, ao menos teoricamente, seria mais democrático. O quadro 2 exibe os indicadores por opção de resposta.

Quadro 2 -

Respostas quantificadas em relação a variável V2 do ICG - 2015.

\begin{tabular}{|c|c|c|}
\hline Alternativa & Texto & Quantificação \\
\hline A & Concurso público apenas & 0,5 \\
\hline B & Eleição apenas & 1 \\
\hline C & Indicação apenas & 0,25 \\
\hline D & Processo seletivo apenas & 0,5 \\
\hline E & Processo seletivo e Eleição & 0,75 \\
\hline F & $\begin{array}{c}\text { Processo seletivo e } \\
\text { Indicação }\end{array}$ & 0,3 \\
\hline G & Outra forma & 0 \\
\hline
\end{tabular}

Fonte: Silva (2017a).

Nesse sentido, os dados do ano de 2015 foram trabalhados em duas vertentes: a) buscando uma atualização do panorama das formas de provimento do diretor escolar no Brasil, em uma exploração mais voltada às escolas que redes de ensino, e; b) categorizar e analisar de forma exploratória redes municipais pela estratificação de três grupos: 0 primeiro de redes municipais de diretores somente eleitos, o segundo de diretores somente indicados e um terceiro heterogêneo, com diversas formas de provimento dentro 
de uma mesma rede municipal, inclusive eleitos ou indicados, utilizando como indicadores exploratórios e um parâmetro quantitativo de comparação, os resultados de proficiências em língua portuguesa e matemática dos anos iniciais do ensino fundamental, o Ideb, o ICQ e o IDHM.

Passa-se a uma breve revisão de literatura acerca da importância da gestão democrática na qualidade da educação, particularizando a discussão para as formas de provimento do diretor escolar.

\section{Gestão democrática, formas de provimento do diretor e a qualidade da educação}

A qualidade da educação tem, ainda que em um contexto mais teórico que empírico, na gestão da escola um de seus pilares para sua concretização. Aspectos como a frequência de reunião dos conselhos de escola, a proposta pedagógica em construção coletiva, a participação da comunidade escolar nos processos decisórios, entre outras, são questões reconhecidas pela literatura (Souza, 2007) como pontos importantes para que a qualidade educacional da escola pública seja efetivada. Nesse sentido, há um destaque na gestão democrática como uma dimensão importante no referido tema. Em contextualização inicial, Moacir Gadotti (2014) afirma que

o tema da gestão democrática da educação com participação popular ganha ainda mais relevância hoje, no momento em que se discute a criação do Sistema Nacional de Educação que define a articulação e a cooperação entre os entes federados. Essa lógica colaborativa só tem sentido se for cimentada pela gestão democrática e tiver por finalidade a construção de uma sociedade livre, justa e solidária, como determina o Inciso I do artigo terceiro da Constituição Federal de 1988. (p. 2)

Alguns documentos nacionais abrangem a referida temática. A gestão democrática dos sistemas de ensino é entendida como "uma das dimensões fundamentais que possibilitam o acesso à educação de qualidade", à formação para a cidadania e como "princípio da educação nacional" da elaboração de "planos de desenvolvimento educacional" e de "projetos político-pedagógicos participativos" (Brasil, 2011, p. 59). Para Dourado (2000) trata-se de um processo de luta política e aprendizado, que não uma prática que não está circunscrita só no ambiente educativo e possibilita um crescimento acerca do conhecimento do jogo democrático e, consequentemente, da reflexão acerca do poder autoritário, visando uma educação democrática.

De forma ampla, neste trabalho interpreta-se a gestão democrática como

a gestão democrática é aqui compreendida, então, como um processo político no qual as pessoas que atuam na/sobre as escolas, identificam problemas, discutem, deliberam e planejam, encaminham, acompanham, controlam e avaliam o conjunto das ações voltadas ao desenvolvimento da própria escola na busca da solução daqueles problemas. Esse processo, sustentado no diálogo, na alteridade e no reconhecimento às especificidades técnicas das diversas funções presentes na escola, tem como base a participação efetiva de todos os segmentos da comunidade escolar, o respeito às normas coletivamente construídas para os processos de tomada de decisões e a garantia de amplo acesso às informações aos sujeitos da escola (Souza, 2009, p. 125). 
Apesar de amplamente trabalhado em vários textos sobre a temática, ressalta-se a gestão democrática do ensino público como um princípio constitucional (Brasil, 1988), reforçado pelo inciso VII do art. 3ํ da lei n. 9.394/96 (Brasil, 1996) e a ênfase do art. 14 da referida lei à participação dos profissionais da educação na elaboração do projeto pedagógico na escola e a participação da comunidade escolar em conselhos escolares ou equivalentes. São questões relevantes, mas insuficientes para a efetividade do envolvimento da comunidade nos processos decisórios.

No entanto, Souza (2007) alerta para uma gestão escolar ser mais ou menos democrática, na qual o diálogo se torna a variável de desequilíbrio entre processos decisórios com mais ou menos envolvimento de outros atores além da direção. $O$ autor entende que a democracia formal, que pauta as eleições de diretores por exemplo, não se efetiva se na prática diária de uma gestão suas ações não se pautarem pelo "diálogo e pela alteridade" (Souza, 2007, p. 144). Bezerra (2009) enfatiza a importância da ação democrática do diretor escolar, visando a um trabalho aperfeiçoado e melhores relações no interior da instituição. Fato é que a efetividade de uma gestão democrática se torna um elemento difícil de ser mensurado e, consequentemente, uma lacuna empírica nas pesquisas em políticas educacionais.

Nesse contexto, destaca-se a forma de provimento enquanto um instrumento de gestão democrática (Souza, 2005), assim como a crítica à indicação política, vista como antidemocrática e uma retroalimentação ao clientelismo e o autoritarismo (Bezerra, 2009). Outros autores, como Dourado (2000), enfatizam o potencial da forma de provimento do diretor escolar por via de eleições diretas pela comunidade da escola. Todavia, Souza (2007) faz uma ressalva ao ressaltar que "o diretor eleito não é, por natureza do processo seletivo, mais compromissado com a educação pública de qualidade para todos”, mas, salienta que "a eleição é o instrumento que, potencialmente, permite à comunidade escolar controlar as ações do dirigente escolar no sentido de levá-lo a se comprometer com esse princípio" (Souza, 2007, p. 189). Outra ressalva é referente ao preparo profissional, ao clientelismo, personalismo do candidato, populismo, entre outros, que são abordados por Bezerra (2009) como problemas na ampliação da eleição de dirigentes após a CF/88. Todavia, esta pesquisa interpreta que, inicialmente, a eleição de diretores é a forma mais democrática e, pelo referencial teórico desta, a que mais se aproxima do conceito de gestão democrática.

Não há clarividência acerca da forma de provimento do diretor escolar como uma dimensão da qualidade educacional e este artigo, pelos seus objetivos e as limitações de um estudo exploratório, não responde a esta indagação, mas oferece um panorama diferenciado para pensar na temática.

\section{Panorama da forma de provimento dos diretores escolares no Brasil}

Nessa seção, pela análise exploratória, busca-se apresentar um panorama das formas de provimento do diretor no Brasil, delimitando as escolas que ofertam os anos iniciais do ensino fundamental e responderam os questionários de contexto do diretor da Prova Brasil de 2015. Para a primeira análise utilizou-se, conforme a tabela 2 , os seguintes casos: 
Tabela 1 -

Casos de diretores de escolas que responderam os questionários de contexto da Prova Brasil de 2015.

\begin{tabular}{c|c|c}
\hline $\begin{array}{c}\text { Dependência } \\
\text { Administrativa }\end{array}$ & Frequência & Percentual em relação às escolas municipais do Brasil \\
\hline Municipal & 34.502 & 40,73 \\
\hline
\end{tabular}

Fonte: Questionários de contexto da Prova Brasil (2015). Inep (2015). Dados trabalhados pelo autor (2017).

Ao agregar as escolas por redes municipais, obtém-se, inicialmente, 5.152 casos, sendo 41 sem resposta. Todavia, nas demais análises exploratórias, nem sempre se consegue essa quantidade de casos, pelos cruzamentos estatísticos realizados que podem revelar ausência de dados nos referidos cotejos. A tabela 2, ainda em contextualização de análise, desagrega as formas de provimento nos casos gerais da análise.

Tabela 2 -

Formas de provimento dos diretores/as das escolas que responderam os questionários de contexto da Prova Brasil de 2015.

\begin{tabular}{c|c|c}
\hline Forma de Provimento & Frequência & Percentual \\
\hline Sem dados & 206 & 6 \\
\hline Concurso Público Apenas & 1.778 & 5,2 \\
\hline Eleição apenas & 6.738 & 19,5 \\
\hline Indicação apenas & 19.904 & 57,7 \\
\hline Processo Seletivo Apenas & 850 & 2,5 \\
\hline Processo Seletivo e Eleição & 2.262 & 6,6 \\
\hline Processo Seletivo e Indicação & 1.814 & 5,3 \\
\hline Outra Forma & 950 & 2,8 \\
\hline Total & 34.502 & 100,0 \\
\hline
\end{tabular}

Fonte: Questionários de contexto da Prova Brasil (2015). Dados trabalhados pelo autor (2017).

A maioria dos diretores foram indicados ao cargo, o que evidencia um cenário de distância da efetividade de uma gestão democrática, ao menos no que tange à eleição direta de dirigentes Entende-se, na perspectiva do envolvimento da comunidade escolar nos processos decisórios que a forma, ainda que imperfeita, de provimento que mais se aproxima da gestão democrática, compreendendo a mesma como uma dimensão das condições de qualidade na oferta educacional, é a eleição direta de diretores (Silva, 2017a; Souza, 2007).

Em todo país há grande variação de resultados, o que evidencia diversas formas de provimento em todo o Brasil e dentro de seus Estados, resultado que dialoga com a dissertação de Silva (2017a).

Entende-se que as formas de provimento com maior profundidade na discussão de seu papel político são a indicação e a eleição de dirigentes (Souza, 2007). Ademais, as distintas possibilidades de assunção ao cargo têm maior ênfase em critérios técnicos. Nesse sentido, optou-se por desagregar os dados predominantemente por três grupos, comparando dois deles: um grupo de redes municipais de diretores somente eleitos, outro de diretores somente indicados e um terceiro grupo composto por dirigentes providos de
Regae: Rev. Gest. Aval. Educ.
Santa Maria
v. 7
n. 16
Set./dez., 2018
p. 41-57 
várias formas, não aprofundadas por este trabalho. Inicialmente, a tabela 3 compara a quantidade de escolas categorizadas por diretores indicados e eleitos por dependência administrativa.

Tabela 3 -

Comparativo de escolas com diretores eleitos e indicados por dependência administrativa - 2015.

\begin{tabular}{|c|c|c|}
\hline Estado & $\begin{array}{l}\text { Escolas com diretores } \\
\text { eleitos - municípios }\end{array}$ & $\begin{array}{l}\text { Escolas com diretores } \\
\text { indicados - municípios }\end{array}$ \\
\hline Rondônia & 124 & 118 \\
\hline Acre & 32 & 8 \\
\hline Amazonas & 17 & 455 \\
\hline Roraima & 1 & 54 \\
\hline Pará & 280 & 1572 \\
\hline Amapá & 11 & 78 \\
\hline Tocantins & 25 & 219 \\
\hline Maranhão & 90 & 1896 \\
\hline Piauí & 133 & 783 \\
\hline Ceará & 8 & 1245 \\
\hline Rio Grande do Norte & 147 & 500 \\
\hline Paraíba & 150 & 613 \\
\hline Pernambuco & 166 & 1322 \\
\hline Alagoas & 194 & 544 \\
\hline Sergipe & 32 & 352 \\
\hline Bahia & 718 & 2869 \\
\hline Minas Gerais & 656 & 1479 \\
\hline Espírito Santo & 176 & 327 \\
\hline Rio de Janeiro & 583 & 1039 \\
\hline São Paulo & 296 & 1765 \\
\hline Paraná & 1169 & 668 \\
\hline Santa Catarina & 140 & 741 \\
\hline Rio Grande do Sul & 758 & 586 \\
\hline Mato Grosso do Sul & 76 & 160 \\
\hline Mato Grosso & 267 & 67 \\
\hline Goiás & 489 & 444 \\
\hline Distrito Federal & 0 & 0 \\
\hline Total & 6738 & 19904 \\
\hline Percentual do Total & 25,29 & 74,71 \\
\hline
\end{tabular}

Fonte: Questionários de contexto da Prova Brasil (2015). Dados trabalhados pelo autor (2017).

A tabela reforça o cenário de indicações ao cargo nas redes municipais, panorama evidenciado em Silva (2017a), mas que carece de discussão política, haja vista que a hipótese é de que em redes municipais menores se caracterizam pelo patrimonialismo, clientelismo e outras ações políticas que privilegiem um pequeno grupo político com maior intensidade que nos grandes centros.

Na próxima seção, a análise dedica-se ao segundo objetivo desse trabalho: analisar, comparativamente, as redes municipais e seus resultados de proficiências da Prova Brasil de 2015, o Ideb, o ICQ e o IDHM, categorizando grupos de redes municipais só com diretores eleitos, indicados ou de diversas formas de provimento. 


\section{Análise exploratória de resultados, indicadores educacionais e de contexto}

Para esta exploração as escolas foram, inicialmente, agregadas por redes e sistemas de ensino, sejam nos cálculos de seus indicadores ou na análise das formas de provimento que categorizaram o município em uma das três estratificações propostas pela pesquisa. Contextualizando a análise que se segue, a tabela 4 indica o panorama quantitativo de redes municipais categorizadas para esse estudo.

Tabela 4 -

Categorização de redes municipais só com diretores eleitos, indicados e de diversas formas de provimento - 2015.

\begin{tabular}{c|c|c}
\hline Formas de Provimento & Casos & Percentual \\
\hline Sem dados & 41 & 0,8 \\
\hline Provimento por indicação & 2963 & 57,5 \\
\hline Diversas formas de provimento & 1801 & 35,0 \\
\hline Provimento por eleição & 347 & 6,7 \\
\hline Total & 5152 & 100,0 \\
\hline
\end{tabular}

Fonte: Questionários de contexto da Prova Brasil (2015). Dados trabalhados pelo autor (2017).

A maior quantidade de casos é do provimento por indicação, já evidenciada nas tabelas anteriores. Destaca-se a o percentual bem menor de redes municipais em que seus diretores são $100 \%$ eleitos, apenas $6,7 \%$ dos casos da pesquisa. A tabela 5 contextualiza esses dados, distribuindo os casos por Estado.

Tabela 5 -

Casos das redes municipais da pesquisa distribuídos por formas de provimento e por estado - 2015.

\begin{tabular}{c|c|c|c|c|c}
\hline Estado & Sem dados & $\begin{array}{c}\text { Provimento } \\
\text { por } \\
\text { indicação }\end{array}$ & $\begin{array}{c}\text { Diversas } \\
\text { formas de } \\
\text { provimento }\end{array}$ & $\begin{array}{c}\text { Provimento } \\
\text { por eleição }\end{array}$ & Total \\
\hline Sem dados & 0 & 9 & 4 & 1 & 14 \\
\hline Acre & 0 & 1 & 16 & 5 & 22 \\
\hline Alagoas & 0 & 60 & 38 & 2 & 100 \\
\hline Amapá & 0 & 6 & 9 & 0 & 15 \\
\hline Amazonas & 0 & 31 & 29 & 1 & 61 \\
\hline Bahia & 0 & 244 & 162 & 9 & 162 \\
\hline Ceará & 0 & 66 & 96 & 0 & 77 \\
\hline Espírito Santo & 0 & 39 & 37 & 1 & 222 \\
\hline Goiás & 2 & 114 & 65 & 41 & 216 \\
\hline Maranhão & 0 & 107 & 109 & 0 & 126 \\
\hline Mato Grosso & 2 & 15 & 45 & 64 & 72 \\
\hline Mato Grosso do & 0 & 40 & 22 & 10 & 779 \\
\hline Sul & & & & & 143 \\
\hline Minas Gerais & 15 & 541 & 183 & 40 & 219 \\
\hline Pará & 0 & 54 & 88 & 1 & 393 \\
\hline Paraíba & 3 & 182 & 34 & 0 & 183 \\
\hline Paraná & 2 & 169 & 124 & 98 & 221 \\
\hline Pernambuco & 0 & 105 & 78 & 0 & 92 \\
\hline Piauí & 2 & 175 & 42 & 2 & 2 \\
\hline Rio de Janeiro & 0 & 35 & 55 & & \\
\hline
\end{tabular}




\begin{tabular}{c|c|c|c|c|c}
\hline $\begin{array}{c}\text { Rio Grande do } \\
\text { Norte }\end{array}$ & 2 & 114 & 37 & 12 & 165 \\
\hline $\begin{array}{c}\text { Rio Grande do } \\
\text { Sul }\end{array}$ & 3 & 215 & 76 & 34 & 328 \\
\hline Rondônia & 0 & 26 & 21 & 4 & 51 \\
\hline Roraima & 0 & 9 & 5 & 0 & 14 \\
\hline Santa Catarina & 2 & 200 & 54 & 6 & 262 \\
\hline São Paulo & 1 & 245 & 343 & 9 & 598 \\
\hline Sergipe & 0 & 60 & 13 & 2 & 75 \\
\hline Tocantins & 7 & 101 & 16 & 3 & 127 \\
\hline Total & 41 & 2963 & 1801 & 347 & 5152 \\
\hline
\end{tabular}

Fonte: Questionários de contexto da Prova Brasil (2015). Dados trabalhados pelo autor (2017).

Os Estados de Goiás, Rio Grande do Sul e Paraná tem os maiores percentuais de redes municipais em que seus diretores são eleitos. Ademais, com exceção do Mato Grosso, em que tem mais grupos de escolas por município com diretores $100 \%$ eleitos do que indicados, todos os estados apresentam maior quantidade contrária. Explorando a Correlação de Pearson do Indicador de Forma de Provimento e das proficiências em Língua Portuguesa e Matemática dos anos iniciais do Ensino Fundamental, evidencia uma correlação positiva, apesar de fraca.

Tabela 6 -

Correlação de Pearson entre o Indicador de Forma de Provimento e as proficiências em Língua Portuguesa e Matemática dos anos iniciais do ensino fundamental 2015.

\begin{tabular}{c|c|c|c}
\hline Estatísticas & Correlação de Pearson & Significância & Casos \\
\hline $\begin{array}{c}\text { Média do Indicador de Forma de } \\
\text { Provimento }\end{array}$ & 1 & & 5.111 \\
\hline Média de Proficiências em LP - Al &, $134^{* *}$ &, 000 & 5.016 \\
\hline Média de Proficiências em MT - Al &, $114^{* *}$ &, 000 & 5.016 \\
\hline
\end{tabular}

Fonte: Questionários de contexto da Prova Brasil e resultados de proficiências (2015). Dados trabalhados pelo autor (2017).

Por esse panorama é de se esperar que as categorizações de grupos evidenciem uma variação razoável, já que as proficiências e a forma de provimento têm correlação fraca. Para isso, o quadro 3 elenca, dentro de cada grupo de redes municipais, os resultados de proficiências, considerando a quantidade de casos e o coeficiente de variação, medido com base no desvio padrão de cada grupo de proficiências e suas médias.

\section{Quadro 3 -}

Média e desvio padrão das proficiências de LP e MT dos anos iniciais e finais do EF categorizadas pelos grupos de redes municipais em que os diretores foram $100 \%$ eleitos, indicados ou providos por diversas formas - 2015.

\begin{tabular}{|c|c|c|c|}
\hline $\begin{array}{l}\text { Formas de } \\
\text { Provimento }\end{array}$ & Estatísticas & $\begin{array}{c}\text { Proficiências LP - } \\
\text { Anos Iniciais }\end{array}$ & $\begin{array}{c}\text { Proficiências MT - } \\
\text { Anos Iniciais }\end{array}$ \\
\hline \multirow{3}{*}{ Indicação } & Media & 197,73 & 211,66 \\
\hline & Casos & 2888 & 2888 \\
\hline & Coeficiente de variação \% & 11,47 & 11,16 \\
\hline Regae: Rev. Gest. Av & Santa Maria & n. 16 & p. $41-57$ \\
\hline
\end{tabular}




\begin{tabular}{|c|c|c|c|}
\hline \multirow{2}{*}{$\begin{array}{c}\text { Demais formas de } \\
\text { provimento }\end{array}$} & Media & 201,32 & 214,91 \\
\cline { 2 - 4 } & Casos & 1718 & 1718 \\
\cline { 2 - 4 } & Coeficiente de variação \% & 10,89 & 10,96 \\
\hline \multirow{3}{*}{ Eleição } & Media & 206,22 & 219,42 \\
\cline { 2 - 4 } & Casos & 342 & 342 \\
\cline { 2 - 4 } & Coeficiente de variação\% & 8,65 & 9,08 \\
\hline \multirow{2}{*}{$\begin{array}{c}\text { Total Indicação } \\
\text { Eleição }\end{array}$} & Media & 198,63 & 32,48 \\
\cline { 2 - 4 } & Casos & 3230 & 11,00 \\
\cline { 2 - 4 } & Coeficiente de variação \% & 11,26 & 3230 \\
\hline
\end{tabular}

Fonte: Questionários de contexto da Prova Brasil e dados de proficiências (2015). Dados trabalhados pelo autor (2017).

Ainda que não se trate de uma grande diferença quantitativa, os resultados indicam que as melhores médias de proficiências, assim como as menores variações, estão no grupo de redes municipais em que os diretores são $100 \%$ eleitos, evidenciadas pelo menor coeficiente de variação em todos os resultados. O resultado indica que se faz necessário um estudo que aprofunde esse fenômeno, pois, a gestão democrática, tida como uma dimensão importante para a qualidade da educação (Souza, 2007; Dourado, Oliveira, Santos, 2007; Silva, 2017a), tem, ao menos quando se agrupa redes municipais em que os diretores/as tiveram o provimento da mesma forma, as escolas em que os dirigentes são eleitos com melhores resultados de proficiências.

Sobre os resultados de desempenho, as correlações de Pearson entre as proficiências de língua portuguesa e matemática são muitos fortes, próximas de 1. Nos dados disponíveis para esta pesquisa, 5057 redes municipais têm resultados de LP e MT e, quando correlacionadas, apresentam, para os anos iniciais, um coeficiente $r=0,958$, evidenciando que, para a grande amplitude de casos, os resultados de LP aumentam na medida que MT cresce, e vice-versa. O gráfico 1 apresenta a dispersão entre os resultados, para os anos iniciais, que materializa o panorama evidenciado pelo teste de correlação.

\section{Gráfico 1 -}

Médias de proficiência em matemática dos anos iniciais, em função das médias de proficiência em língua portuguesa das redes municipais de ensino do Brasil - 2015.

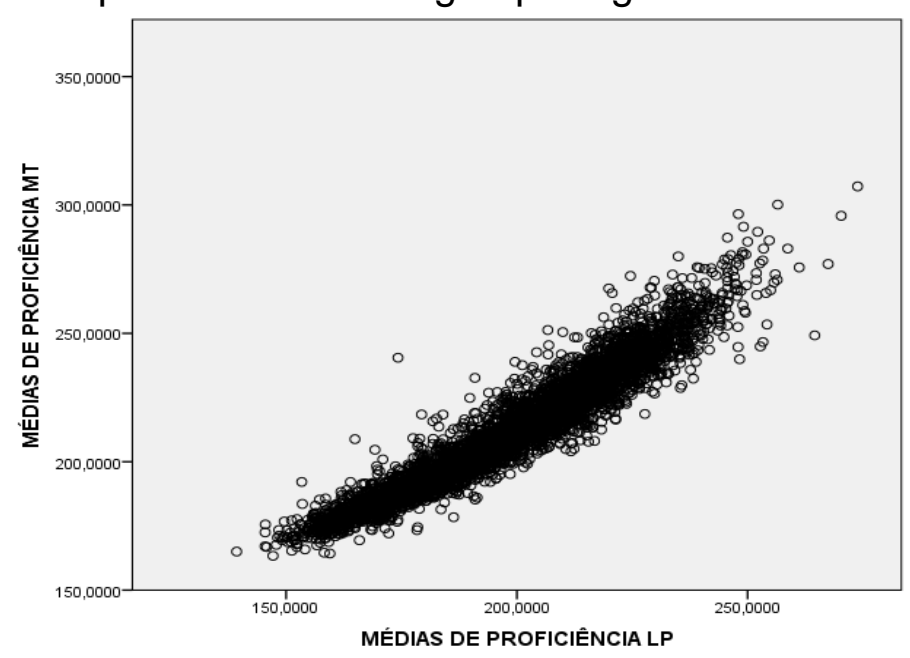

Fonte: Questionários de contexto da Prova Brasil (2015). Dados trabalhados pelo autor (2017). 
O formato da combinação de resultados de LP e MT evidenciam a forte correlação trabalhada no parágrafo anterior. Este panorama permite, para esse estudo, complementar a discussão com um cenário de distribuição de resultados por forma de provimento, usando como base apenas uma das proficiências trabalhadas no estudo, tendo em vista que, pela forte correlação, o percentual de distribuição e, consequentemente, do coeficiente gamma, será muito próximo para qualquer outro resultado de desempenho. Para isso, optou-se, para a tabela abaixo, o trabalho com as proficiências em língua portuguesa dos anos iniciais do ensino fundamental.

Tabela 8 -

Distribuição dos casos por nível de proficiência nas formas de provimento - 2015.

\begin{tabular}{|c|c|c|c|c|c|c|}
\hline $\begin{array}{l}\text { Níveis de } \\
\text { Proficiência }\end{array}$ & Descrição do dado & $\begin{array}{l}\text { Sem } \\
\text { dados }\end{array}$ & $\begin{array}{l}\text { Provimento } \\
\text { por } \\
\text { indicação } \\
\end{array}$ & $\begin{array}{c}\text { Diversas } \\
\text { formas de } \\
\text { provimento }\end{array}$ & $\begin{array}{l}\text { Provimento } \\
\text { por eleição }\end{array}$ & Total \\
\hline \multirow{2}{*}{$<=150$} & Casos & 0 & 10 & 4 & 0 & 14 \\
\hline & \% Provimento & $0,0 \%$ & ,3\% & ,2\% & $0,0 \%$ & ,3\% \\
\hline \multirow{2}{*}{$150 ; 175[$} & Casos & 6 & 551 & 272 & 17 & 846 \\
\hline & \% Provimento & $14,6 \%$ & $19,1 \%$ & $15,2 \%$ & $5,0 \%$ & $16,7 \%$ \\
\hline \multirow{2}{*}{$175 ; 200[$} & Casos & 11 & 950 & 518 & 103 & 1582 \\
\hline & \% Provimento & $26,8 \%$ & $32,9 \%$ & $29,0 \%$ & $30,1 \%$ & $31,3 \%$ \\
\hline \multirow{2}{*}{ [200;225[ } & Casos & 18 & 1035 & 760 & 173 & 1986 \\
\hline & \% Provimento & $43,9 \%$ & $35,8 \%$ & $42,6 \%$ & $50,6 \%$ & $39,3 \%$ \\
\hline \multirow{2}{*}{ [225;250[ } & Casos & 6 & 329 & 222 & 48 & 605 \\
\hline & \% Provimento & $14,6 \%$ & $11,4 \%$ & $12,4 \%$ & $14,0 \%$ & $12,0 \%$ \\
\hline \multirow{2}{*}{$>=250$} & Casos & 0 & 13 & 10 & 1 & 24 \\
\hline & \% Provimento & $0,0 \%$ &, $5 \%$ &, $6 \%$ & ,3\% &, $5 \%$ \\
\hline \multirow{2}{*}{ Total } & Casos & 41 & 2888 & 1786 & 342 & 5057 \\
\hline & \% Provimento & $100,0 \%$ & $100,0 \%$ & $100,0 \%$ & $100,0 \%$ & $100,0 \%$ \\
\hline
\end{tabular}

Fonte: Questionários de contexto da Prova Brasil e resultados de proficiências (2015). Dados trabalhados pelo autor (2017).

Assim como as correlações de Pearson baixas em relação à forma de provimento e os resultados de proficiências, o coeficiente gamma também é fraco, de 0,138 , muito próximo do $r$ registrado no teste de Pearson. Para esta tabela, optou-se por classificar as proficiências de acordo com as escalas propostas pelo Inep para a Prova Brasil aplicada aos $5^{\circ}$ s anos, elencando desde o nível 1 ao 9 . Todavia, os resultados apresentados são distribuídos somente até o nível 6, ou seja, entre 250 e 275 de proficiência. Pelos coeficientes testados, não há uma distribuição valorativa e ordinal. Todavia, a concentração de casos nos níveis 3,4 e 5 das redes municipais de diretores eleitos é de $94,7 \%$, maior no comparativo entre as demais categorizações, $84 \%$ em formas variadas de provimento e $80,1 \%$ no grupo de escolas com diretores indicados.

Elucidando esse cenário de maior homogeneidade, comparando as categorizações de redes municipais, o gráfico 2 auxilia no entendimento da variação/dispersão dos resultados. 
Gráfico 2 -

Dispersão das proficiências dos anos iniciais de LP e MT por grupo de redes municipais em que os diretores foram providos só por eleição, indicação ou em diversas formas de provimento - 2015.

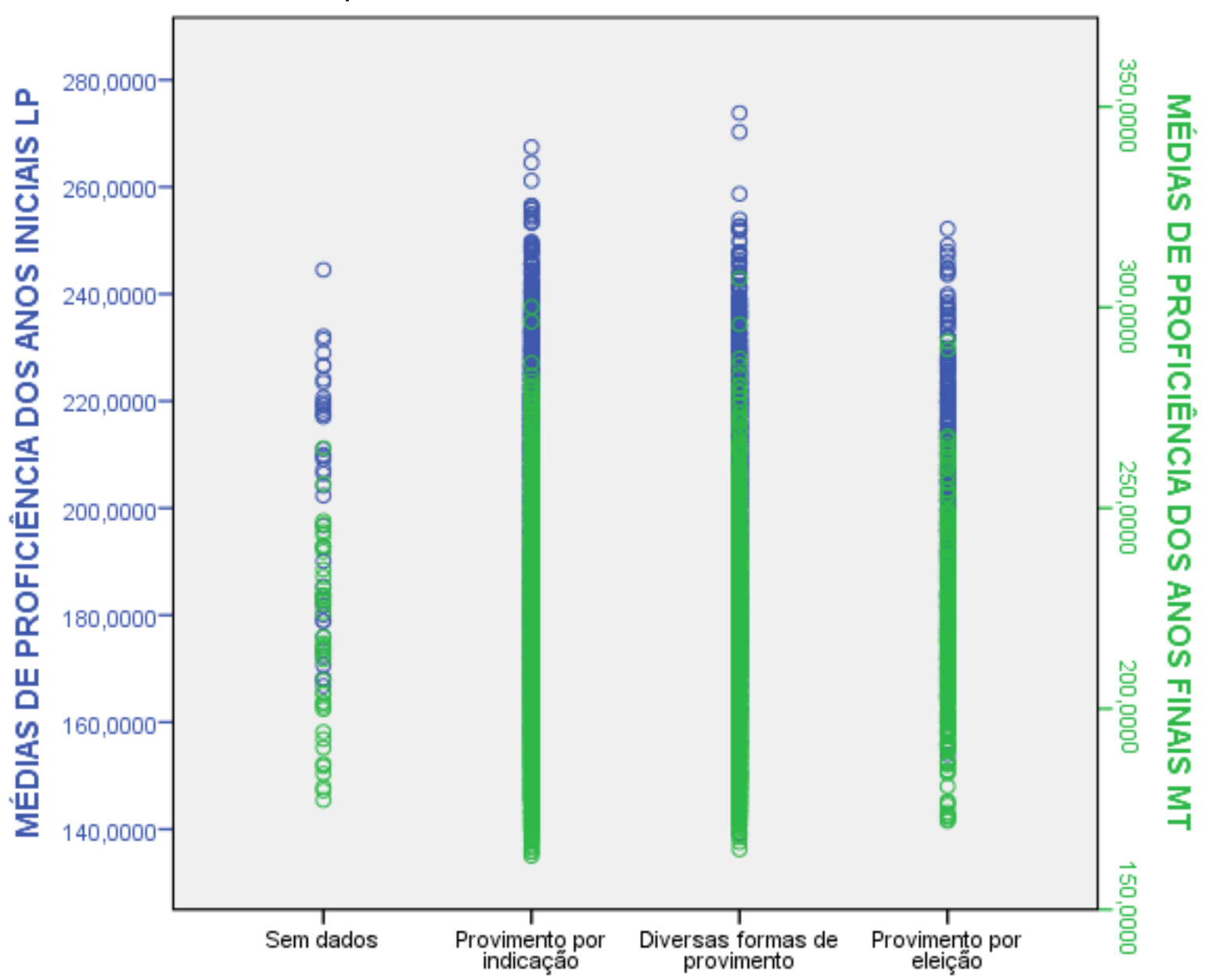

Formas de provimento

Fonte: Questionários de contexto da Prova Brasil e resultados de proficiências (2015). Dados trabalhados pelo autor (2017).

O gráfico evidencia maior homogeneidade dos resultados do grupo de redes municipais de diretores eleitos. Todavia, a maior quantidade de casos dos outros grupos caracteriza a possibilidade de maior dispersão. Os dados apresentados anteriormente, juntamente com o gráfico acima apresentam que, apesar de alguns poucos casos com maiores proficiências no grupo de indicação, o outro grupo é mais coeso e com melhor desempenho.

Com a exploração das proficiências da Prova Brasil, as análises que se seguem visam observar, dentro de tais grupos, os resultados de ICQ, IDHM e IDEB. Inicialmente, a tabela abaixo elenca um panorama quantitativo de tais indicadores por grupo de redes municipais categorizado. 
Tabela 8 -

IDHM, ICQ e IDEB distribuídos por grupos de redes municipais por provimento do diretor e por quartis - 2015.

\begin{tabular}{c|r|r|r|r|r|r|r}
\hline Medidas & \multicolumn{1}{c|}{ Casos } & \multicolumn{1}{c|}{ Média } & Mediana & $\begin{array}{c}\text { Desvio } \\
\text { padrão }\end{array}$ & Até $25 \%$ & 25 a $50 \%$ & 50 a $75 \%$ \\
\hline $\begin{array}{c}\text { IDHM - Outras } \\
\text { formas }\end{array}$ & 1798 &, 67139 &, 68400 &, 078188 &, 60600 &, 68400 &, 73500 \\
\hline IDHM - Indicação & 2962 &, 64456 &, 64200 &, 068887 &, 58875 &, 64200 &, 70300 \\
\hline IDHM - Eleição & 347 &, 68627 &, 69100 &, 049519 &, 66400 &, 69100 &, 71700 \\
\hline $\begin{array}{c}\text { ICQ 2015 - Outras } \\
\text { formas }\end{array}$ & 1766 &, 5880 &, 5884 &, 09232 &, 5226 &, 5884 &, 6531 \\
\hline $\begin{array}{c}\text { ICQ 2015 - } \\
\text { Indicação }\end{array}$ & 2704 &, 5626 &, 5587 &, 09488 &, 5000 &, 5587 &, 6273 \\
\hline $\begin{array}{c}\text { ICQ 2015 - } \\
\text { Eleição }\end{array}$ & 315 &, 6269 &, 6266 &, 08616 &, 5650 &, 6266 &, 6873 \\
\hline $\begin{array}{c}\text { IDEB 2015 - } \\
\text { Outras formas }\end{array}$ & 1792 & 5,313 & 5,400 & 1,0554 & 4,500 & 5,400 & 6,100 \\
\hline $\begin{array}{c}\text { IDEB 2015 - } \\
\text { Indicação }\end{array}$ & 2916 & 5,038 & 5,200 & 1,3997 & 4,300 & 5,200 & 6,000 \\
\hline $\begin{array}{c}\text { IDEB 2015 - } \\
\text { Eleição }\end{array}$ & 342 & 5,491 & 5,500 & 1,0587 & 5,100 & 5,500 & 6,100 \\
\hline
\end{tabular}

Fonte: Inep (2017). IBGE (2017). Dados trabalhados pelo autor (2017).

Todas as comparações seguem um padrão: as maiores médias e as menores variações estão no grupo de redes municipais em que os dirigentes foram eleitos, seguido do grupo das outras formas de provimento, deixando a categoria de redes municipais com diretores $100 \%$ indicados com os piores indicadores e resultados. Esse panorama tende a ser o mesmo dentro dos quartis. Exceção se dá ao Ideb, onde a variação do primeiro grupo citado é maior que o segundo, assim como o IDHM do terceiro quartil, em que o segundo grupo supera no maior resultado, e não necessariamente na média e na homogeneidade.

No gráfico abaixo comparam-se ICQ e IDHM, tendo em vista suas escalas serem congruentes. O panorama da tabela anterior é redesenhado graficamente, buscando maior compreensão da análise realizada acima.

Gráfico 3 -

Comparativo de médias do ICQ e do IDHM por grupos de redes municipais categorizados em suas formas de provimento do diretor - 2015.

\begin{tabular}{|c|c|c|c|c|c|}
\hline 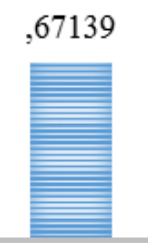 & 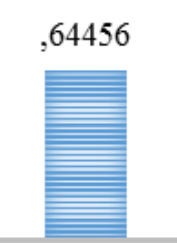 & 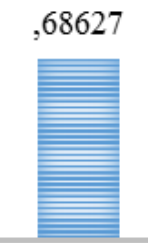 & ,5880 & 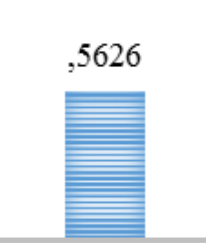 & ,6269 \\
\hline $\begin{array}{l}\text { IDHM - } \\
\text { Outras } \\
\text { formas }\end{array}$ & $\begin{array}{l}\text { IDHM - } \\
\text { Indicação }\end{array}$ & $\begin{array}{l}\text { IDHM - } \\
\text { Eleição }\end{array}$ & $\begin{array}{c}\text { ICQ } 2015 \text { - } \\
\text { Outras } \\
\text { formas }\end{array}$ & $\begin{array}{l}\text { ICQ } 2015 \text { - } \\
\text { Indicação }\end{array}$ & $\begin{array}{c}\text { ICQ } 2015 \text { - } \\
\text { Eleição }\end{array}$ \\
\hline & IDHM & & & ICQ & \\
\hline
\end{tabular}

Fonte: IBGE (2017). Inep (2017). Dados Trabalhados pelo Autor (2017). 
As maiores médias estão no grupo em que os diretores são eleitos, cenário que se repete com o Ideb. Ressalta-se que no caso do IDHM, um indicador social e econômico, existem várias possibilidades de interpretação e investigação. Destaca-se duas: um contexto social e econômico privilegiado sendo um impulsionador de práticas democráticas naquela sociedade local ou o panorama social e econômico privilegiado sendo um dos fatores de causalidade de melhores resultados e condições de qualidade na oferta educacional e não exatamente a gestão democrática ou, em particular para esse estudo, a forma de provimento.

A literatura qualifica a forma de provimento do diretor escolar como uma dimensão da gestão democrática e esta da qualidade educacional (Gadotti, 2014; Souza, 2007; Souza 2009; Silva, 2017a; Dourado, 2000; Bezerra, 2009). Portanto, observar um panorama em que há uma diferença, variando entre 5\% e 20\%, nos resultados e indicadores educacionais quando se compara grupos de redes municipais em que os diretores são $100 \%$ eleitos, indicados ou de outras formas e evidencia a diferenciação citada a favor do primeiro grupo, a análise exploratória consegue, no limite de suas análises, trazer, ao menos, um cenário de homogeneidade maior a este grupo, o que permite trazer mais questionamentos e possibilidades de estudos empíricos que investiguem a temática.

\section{Considerações finais}

As análises desse trabalho evidenciaram alguns aspectos trabalhados na literatura acadêmica, em particular no que se refere à distância da efetividade da gestão democrática nas escolas das redes municipais do país (Souza, 2007; Souza, 2009; Silva, 2017a). Na amostra de mais de $40 \%$ das escolas municipais que ofertam os anos iniciais do ensino fundamental, o quadro para 2015 evidencia a predominância de indicações como forma de provimento ao cargo de diretor escolar no Brasil.

Além disso, a análise dos resultados de proficiências de Língua Portuguesa e Matemática da Prova Brasil de 2015, dentro dos grupos de redes municipais só com diretores eleitos, indicados ou por diversas formas de provimento, evidenciaram que, no primeiro grupo, os desempenhos dos alunos são, considerando o conjunto de resultados, maiores na média, menores nas variações e, consequentemente, com maior homogeneidade, em comparação aos outros grupos, especialmente, para essa análise, das escolas das redes municipais que indicaram todos os seus diretores.

O mesmo cenário é desenhado ao comparar os três grupos em relação ao ldeb, IDHM e ICQ. Em todos os casos, as variações são menores e as médias são maiores no grupo das redes municipais em que os diretores foram $100 \%$ eleitos, cenário oposto ao grupo de diretores indicados.

Evidentemente que se trata de um estudo inicial e, como tal, elenca apenas indícios. A esse despeito, o efeito da gestão democrática do ensino público enquanto princípio da educação nacional, em particular na eleição do seu dirigente, necessita de maior aprofundamento empírico, particularmente no que tange à sua efetividade na qualidade da educação, seja no desenvolvimento da democracia na escola em seus processos decisórios ou a reflexão desse processo na possível influência em maiores resultados de proficiências e aprendizagem. 


\section{Referências}

BEZERRA, Aldenice Alves. Modalidade de provimento do dirigente escolar: mais um desafio para as políticas da educação municipal. Revista Brasileira de Estudos Pedagógicos, Brasília, v. 90, n. 224, 2009, p. 59-70.

BRASIL. Constituição da República Federativa do Brasil. Brasília: Senado Federal, 1988.

BRASIL. Lei n. 9.394 de 20 de dezembro de 1996. Estabelece a Lei de Diretrizes e bases da Educação Nacional. 1996. Diário Oficial da República Federativa do Brasil, Brasília, 23 dez. 1996. Disponível em <http://www.planalto.gov.br/ccivil_03/leis/19394.htm>. Acesso em 11 mar. 2017.

BRASIL. Secretaria Geral da Presidência da República. Democracia participativa: nova relação do estado com a sociedade. Brasília: Serrana, 2011.

DOURADO, Luís Fernandes. A escolha de dirigentes escolares: políticas e gestão da educação no Brasil. In: FERREIRA, Naura Syria Carapeto (org.). Gestão democrática da educação: atuais tendências, novos desafios. São Paulo: Cortez, 2000, p. 77-95.

GADOTTI, Moacir. Gestão democrática com participação popular no planejamento e na organização da educação nacional. Brasília: MEC, 2014.

GOUVEIA, Andrea Barbosa; SOUZA, Ângelo Ricardo de; SCHNEIDER, Gabriela. Índice de condições de qualidade educacional: metodologia e indícios. Estudos em Avaliação Educacional, São Paulo, v. 22, n. 48, 2011, p. 115-135.

INSTITUTO NACIONAL DE ESTUDOS E PESQUISAS EDUCACIONAIS ANÍSIO TEIXEIRA. Brasília: Ministério da Educação, 1937. Disponível em <http://www.inep.gov.br/>. Acesso em 4 jun. 2017.

PARO, Vitor Henrique. O princípio da gestão escolar democrática no contexto da LDB. In: OLIVEIRA, Romualdo Portela de; ADRIÃO, Theresa (org.). Gestão financiamento e direito à educação: análise da LDB e da Constituição Federal. São Paulo: Xamã, 2007, p. 73-91.

SCHNEIDER, Gabriela; SILVA, Marcus Quintanilha da. Índice de nível socioeconômico dos alunos do $5^{\circ}$ ano do ensino fundamental: descrição de metodologia e análise de dados. SIMPÓSIO BRASILEIRO DE POLÍTICA E ADMINISTRAÇÃO DA EDUCAÇÃO, 27, 2015. Anais ... Salvador: Anpae, v. 21, 2015, p. 1-14.

SILVA, Marcus Quintanilha da. Condições de qualidade das redes municipais de ensino fundamental no Brasil. Curitiba: UFPR, 2017a. 227f. Dissertação (mestrado em Educação). Programa de Pós-Graduação em Educação, Universidade Federal do Paraná.

SILVA, Marcus Quintanilha da. Estado regulador, avaliador e o índice de desenvolvimento da educação básica: virtudes e limites do indicador. CONGRESSO NACIONAL DE EDUCAÇẨO - EDUCERE, 8, 2017b. Anais ... Curitiba: Champagnat, 2017b.

SOUZA, Ângelo Ricardo de; GOUVEIA, Andrea Barbosa; SILVA, Mônica Ribeiro da; SCHWENDLER, Sônia de Fátima. Gestão democrática da escola pública. In: SOUZA, Ângelo Ricardo de (org.). Coleção gestão e avaliação da escola pública. Curitiba: UFPR, 2005.

SOUZA, Ângelo Ricardo de. Perfil da gestão da escola no Brasil. São Paulo: PUC, 2007. 302f. Tese (doutorado em Educação). Programa de Pós-Graduação em Educação, Pontifícia Universidade Católica.

SOUZA, Ângelo Ricardo de. Explorando e construindo um conceito de gestão democrática. Educação em Revista, Belo Horizonte, v. 25, n. 3, 2009, p. 123-140. 
Marcus Quintanilha da Silva é professor substituto na Universidade Federal do Paraná, mestre em Educação pela Universidade Federal do Paraná.

Endereço: Rua General Carneiro, 460 - 80060-150 - Curitiba - PR - Brasil.

E-mail: marcusquintanlha@hotmail.com.

Recebido em 29 de março de 2018.

Aceito em 12 de junho de 2018.

(c) (i) 